\title{
Duodenal obstruction from congenital bands: An unusual cause of pancreatitis
}

\author{
JD JUST MD, RJ BAILEY MD FRCPC
}

\begin{abstract}
JD JUST, RJ BAILEY. Duodenal obstruction from congenital bands: An unusual cause of pancreatitis. Can J Gastroenterol 1996;10(7):449-450. Acute pancreatitis in children has many different causes. An unusual case of pancreatitis is presented, along with a review of some of the factors associated with pancreatitis in children. The probable pathogenesis of pancreatitis in this case is also discussed.
\end{abstract}

Key Words: Congenital bands, Duodenal obstruction, Pancreatitis

A cute pancreatitis, while uncommon in children, is not rare. It can be due to a variety of causes including gallstones, trauma, drugs and congenital abnormalities leading to obstruction of the pancreatic duct (1). We present an unusual case of recurrent acute pancreatitis secondary to a congenital anomaly.

\section{CASE PRESENTATION}

A 16-year-old female presented to a rural hospital with a $5 \mathrm{~h}$ history of nausea and vomiting associated with severe epigastric pain. She was found to have an elevated white blood cell count of $13.8 \times 10^{9} \mathrm{cells} / \mathrm{L}$ and an elevated amylase of 400 Somogyi units (normal less than 150). Other admission bloodwork including the remainder of the complete blood count, lactate dehydrogenase, aspartate aminotransferase, alkaline phosphatase and bilirubin were all within normal limits. Her symptoms quickly improved with nasogastric suction and intravenous hydration. An intravenous cholangiogram was performed and was normal. The nasogastric tube was removed after two days but symptoms quickly recurred. Her repeat amylase was 740 Somogyi units. The patient was referred to a tertiary centre.

\section{Obstruction duodénale due à des bandes congénitales : cause rare de pancréatite}

RÉSUMÉ : La pancréatite aiguë a plusieurs causes chez les enfants. Un cas rare de pancréatite est présenté ici, de même qu'une revue de certains des facteurs associés à la pancréatite chez l'enfant. La pathogenèse probable de la pancréatite dans ce cas est également présentée.

Abdominal ultrasound revealed a normal gallbladder and extrahepatic biliary tree, no evidence of cholelithiasis, and mild edema of the pancreatic head. A gastroscopy showed an acute angle at the second part of her duodenum and the possibility of an annular pancreas was considered. Subsequent endoscopic retrograde cholangiopancreatography (ERCP) was normal. Symptoms improved again and the patient was able to resume oral intake and was discharged home. Three days later she had recurrence of symptoms and was readmitted. Her amylase was 600 Somogyi units and repeat bilirubin and alkaline phosphatase were normal. Serum calcium, cholesterol, triglycerides and gastrin were all normal. Viral studies for mumps and Epstein-Barr virus were negative. Her symptoms resolved with nasogastric suction but recurred one day after she resumed oral intake.

A contrast upper gastrointestinal series was performed and showed duodenal spasm and partial obstruction at the fourth part of the duodenum. She was subsequently taken to the operating room and found to have partial malrotation of the bowel with the cecum in the left upper quadrant and bands obstructing the fourth part of the duodenum. She did not have situs inversus. Five bands were divided, the small bowel

Royal Alexandra Hospital, Edmonton, Alberta

Correspondence: Dr RJ Bailey, Suite 310, Hys Centre, 11010 - 101 Street, Edmonton, Alberta T5H 4B9. Telephone 403-421-1029, fax 403-425-5533

Received for publication June 20, 1995. Accepted November 22, 1995 
was placed on the right side of the abdomen, the large bowel was placed on the left side of the abdomen, and an incidental appendectomy was performed. She recovered quickly postoperatively and was discharged home. She has had no further episodes of pancreatitis in the 13 years since surgery.

\section{DISCUSSION}

Acute pancreatitis in children has many different underlying etiologies. In many series, blunt trauma is the most common initiating factor $(2,3)$. Pancreatitis is also commonly seen as part of multisystem diseases such as Reye syndrome, shock, hemolytic-uremic syndrome, and viral infections (4). Children receiving treatment for acute leukemia with steroids and L-asparaginase also make up a large percentage of the cases of acute pancreatitis in some series $(2,5)$. Hereditary, pancreatitis can also present during childhood (6). Most large series also show a significant number of children with idiopathic pancreatitis for which no underlying cause is found (2-4). However, with more aggressive investigation including ERCP an underlying cause is more frequently being identified (7).

Congenital anomalies are being found to be common in many of these 'idiopathic' cases (5). Current reviews have listed a number of these congenital causes of recurrent pancreatitis such as congenital anomalies of the pancreatic ducts, choledochal cysts, and aberrant gastroduodenal artery causing ductal obstruction in the head of the pancreas $(8,9)$. Acute pancreatitis associated with gastric volvulus in a congenital diaphragmatic hernia has also been reported (10).

In a review, Stewart and colleagues (11) state that malrotation of the bowel can be seen incidentally in $0.2 \%$ of barium studies of the gastrointestinal tract and may remain asymptomatic. However, most of these patients present before the age of one month with features of a bowel obstruction. This obstruction is usually from a small bowel volvulus around the narrow root of the small bowel mesentery but occasionally the obstruction is caused by congenital bands.

\section{REFERENCES}

1. Roberts IM. Disorders of the pancreas in children. Gastroenterol Clin North Am 1990;19:963-73.

2. Vane DW, Grosfeld JL, West KW, Rescorla FJ. Pancreatic disorders in infancy and childhood: Experience with 92 cases. J Pediatr Surg 1989;24:771-6.

3. Tam PKH, Saing H, Irving IM, Lister J. Acute pancreatitis in children. J Pediatr Surg 1985;20:58-60.

4. Weizman Z, Durie PR. Acute pancreatitis in childhood. J Pediatr 1988;113:24-9.

5. Synn AY, Mulvihill SJ, Fonkalsrud EW. Surgical disorders of the pancreas in infancy and childhood. Am J Surg 1988;156:201-5.

6. Chishan RK, Greene HL, Avant G, O’Neill J, Neblett W. Chronic relapsing pancreatitis in childhood. J Pediatr 1983;102:514-8.

7 Grendell JH. Idiopathic acute pancreatitis. Gastroenterol Clin North Am 1990;19:843-7.

8. Carey LC. Recurrent acute pancreatitis - Rarely idiopathic: 1989 Du Pont Lecture. Can J Surg 1990;33:107-12.

9. Leese T, Chiche L, Bismuth H. Pancreatitis caused by congenital anomalies of the pancreatic ducts. Surgery 1989;105:125-30.

10. Oliver MJ, Wilson ARM, Kapila L. Acute pancreatitis and gastric
Typically, bands seen in this disorder cause obstruction of the second portion of the duodenum (12). Pancreatitis has not been reported as a presentation of this anomaly in the English literature. However, in the case presented in this article, there was no volvulus and the obstruction was from abnormal bands across the fourth part of the duodenum.

Pancreatitis has been reported in adults with afferent loop syndrome following gastric surgery (13). This is caused by obstruction of the afferent loop with resulting dilation of the duodenum and increased back pressure on the pancreatic and biliary ductal systems (14). Acute pancreatitis may also be seen in children with gastrointestinal duplications $(15,16)$. Both of these causes of pancreatitis involve duodenal obstruction beyond the ampulla of Vater. A similar mechanism has been used to induce experimental pancreatitis in dogs by tying off the duodenum to create a closed loop obstruction of the duodenum (17). All of these examples of pancreatitis appear to have a similar mechanism to what may have occurred in our patient. She had congenital bands obstructing the fourth part of the duodenum that may have caused a closed loop obstruction of the duodenum leading to pancreatitis.

When a child presents with acute pancreatitis and no obvious etiology such as trauma, drugs, infection, gallstones, or systemic disease, a congenital anomaly should be suspected. This is especially true in children with recurrent acute pancreatitis. Abdominal ultrasound and computed tomography will identify most choledochal cysts and gastrointestinal duplication cysts. Visualization of pancreatic ductal anatomy with ERCP is particularly important to rule out congenital anomalies of the ductal system or other obstructive causes. We suggest that congenital bands causing duodenal obstruction also be considered a potential cause of pancreatitis in children. A contrast study of the upper gastrointestinal tract will identify these cases. With increased identification of the underlying cause, optimal treatment and prevention of recurrence can be obtained.

volvulus occurring in a congenital diaphragmatic hernia. J Pediatr Surg 1990;25:1240-1.

11. Stewart DR, Colody AL, Daggett WC. Malrotation of the bowel in infants and children: A 15 year review. Surgery 1976;79:716-20.

12. Ladd WE. Congenital obstruction of the duodenum in children. N Engl J Med 1932;206:277.

13. Brook-Cowden GL, Braasch JW, Gibb SP, et al. Postgastrectomy syndromes. Am J Surg 1976;131:464-70.

14. Eagon JC, Miedema BW, Kelly KA. Postgastrectomy syndromes. Surg Clin North Am 1992;72:445-65.

15. Lavine JE, Harrison M, Heyman MB. Gastrointestinal duplications causing relapsing pancreatitis in children. Gastroenterology 1989;97:1556-8.

16. Black PR, Welch KJ, Eraklis AJ. Juxtapancreatic intestinal duplications with pancreatic ductal communication: A cause of pancreatitis and recurrent abdominal pain in childhood. J Pediatr Surg 1986;21:257-61.

17. Pfeffer RB, Stasior O, Hinton JW. The clinical picture of the sequential development of acute pancreatitis in the dog. Surg Forum $1957 ; 8: 248-51$. 


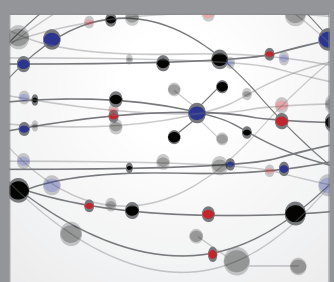

The Scientific World Journal
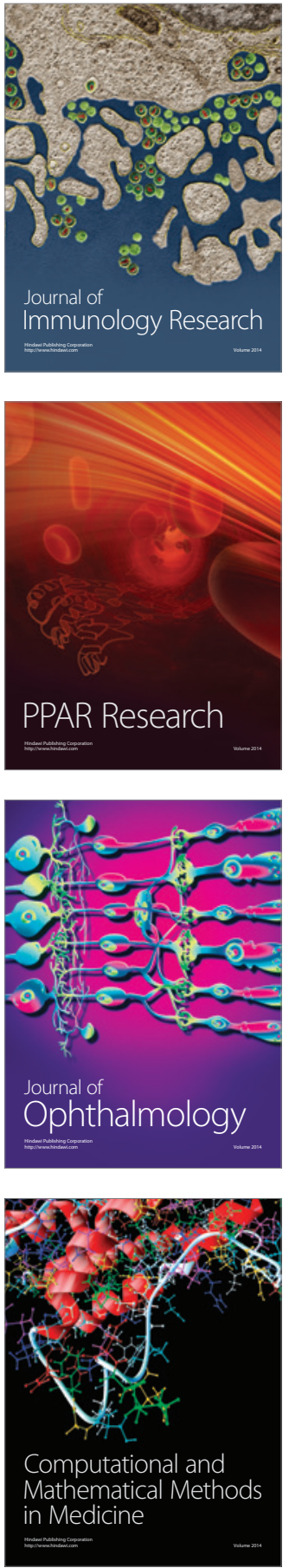

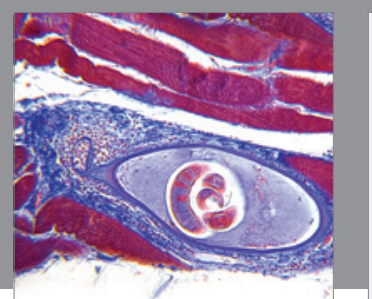

Gastroenterology Research and Practice

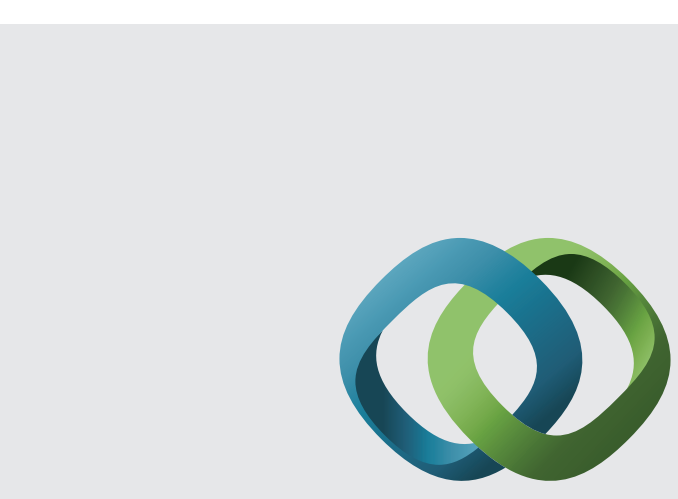

\section{Hindawi}

Submit your manuscripts at

http://www.hindawi.com
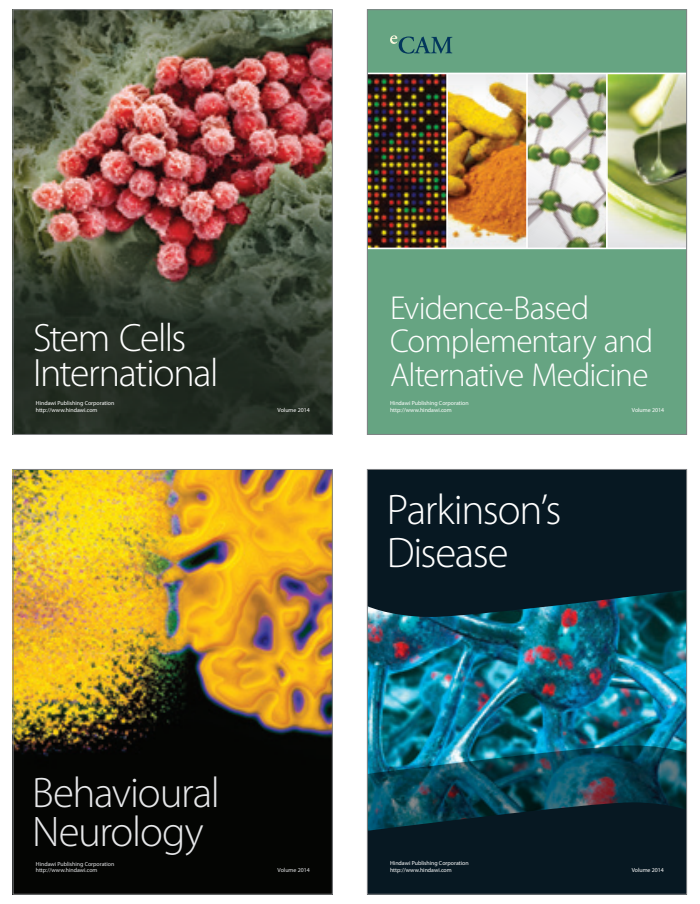
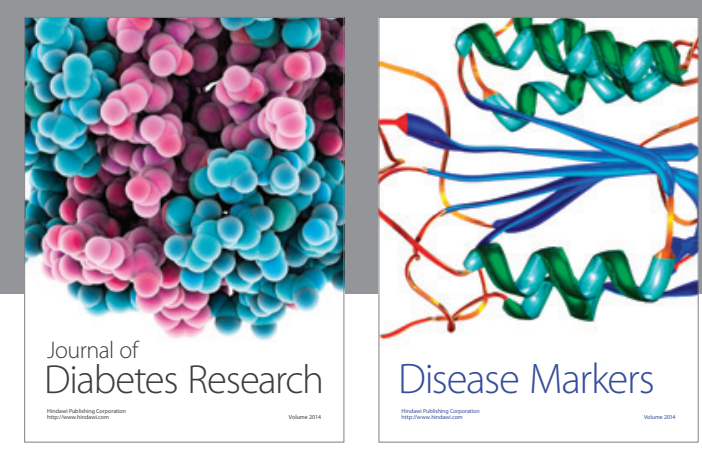

Disease Markers
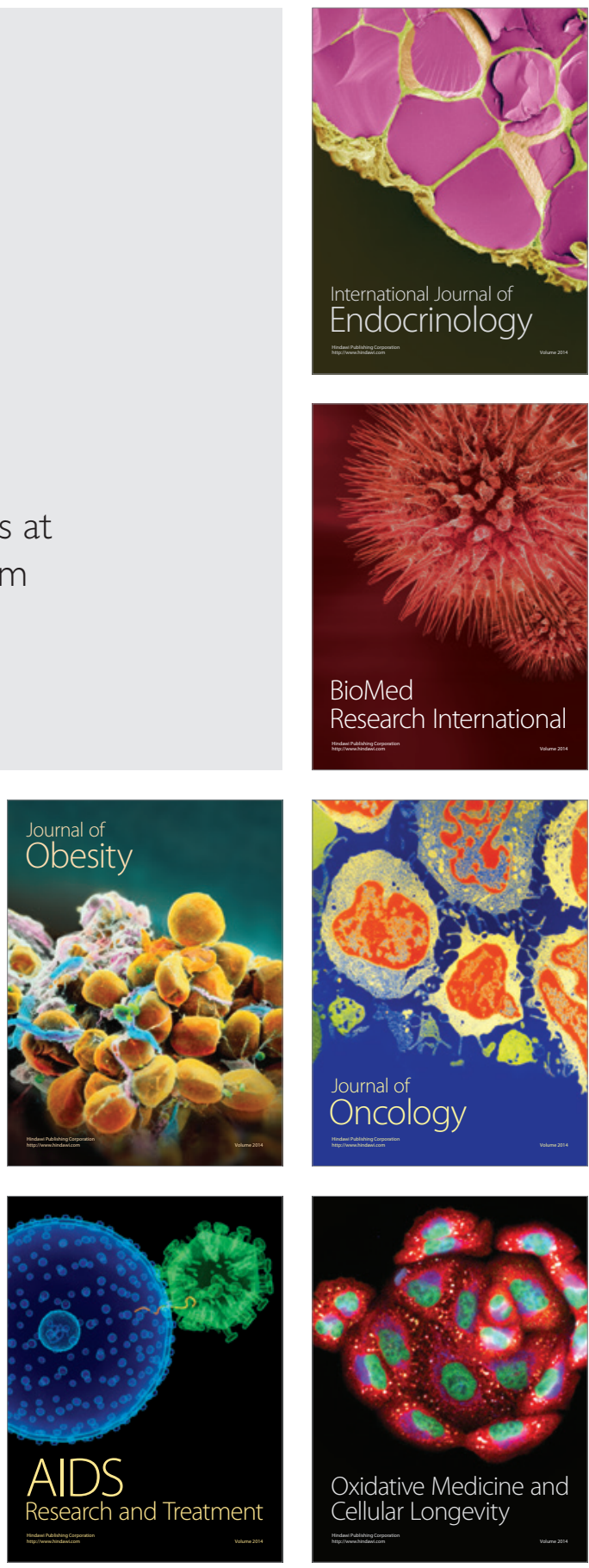